\title{
The merits of varying forms of mass timber products for offsite and modular construction
}

\author{
Robert HAIRSTANS ${ }^{1 *}$, Ryan SMITH ${ }^{2}$ and Peter WILSON ${ }^{3}$ \\ ${ }^{1}$ Associate Professor, Institute for Sustainable Construction, Edinburgh Napier University \\ ${ }^{2}$ Associate Professor, School of Architecture, the University of Utah \\ ${ }^{3}$ Director, Timber Design Iniatives \\ *Corresponding author's e-mail: r.hairstans@napier.ac.uk
}

\begin{abstract}
Mass timber is a family of Solid Laminate Timber Systems (SLTS) formed from smaller sections of timber connected by glue, mechanical fixings, moisture movement or a combination of methods. These products, which include Structural Composite Lumber, GluLam, Cross Lam, Nail Lam and Dowel Lam (or Brettstapel), have over the past two decades seen an extraordinary upsurge in use internationally. This global phenomenon has been driven by a greater emphasis on the sustainable use of renewable resources and by significant technological developments in the manufacture of SLTS. This research paper considers the merits of each of these products, their manufacturing processes and the corresponding quality assurance requirements necessary for successful project delivery. The paper describes the advantages and barriers to the use of the mass timber and provides an overview of the various aspects to be considered during design for offsite and modular construction. The work presented also provides case studies of how these products have been researched and utilised into live projects in the UK utilising local resource resulting in the formation of new supply chain arrangements. The work further explains the advantages of the respective systems for the given application including information on species selection, connection systems employed and the necessary onsite and offsite management approaches deployed.
\end{abstract}

\section{KEYWORDS}

Mass Timber, Solid Laminate Timber Systems, Offsite, Modular, Structural Composite Lumber, Glulam, Cross Lam (CLT), Nail Lam (NLT), Dowel Lam (DLT), Timber

\section{INTRODUCTION}

Globally the production of mass timber systems is increasing exponentially, driven by the need for more sustainable ways of delivering the built environment and the technological advances being made mechanically and digitally. Coinciding with this is also the global shift to carrying out more construction activities offsite in a factory environment. Mass timber slab and beam components can be brought together and combined with other materials to form modular or volumetric units which are capable of being enhanced with internal and external finishes. Further, services can also be included in order to create turnkey solutions. This paper reviews the various forms of mass timber products for such applications including the advantages and 
barriers to uptake. The onset and interoperability of digital platforms and their potential to improve the design for manufacture and assembly and disassembly are also considered. Finally the explorative research of mass timber systems in a UK context is presented with an emphasis on the utilisation of Scottish timber resource for production. This research includes case examples of pilot application and an overview of how the derived information from this has been disseminated to stimulate the market.

\section{MASS TIMBER}

\section{Overview of Products}

There are various forms of Solid Laminate Timber Systems which make up the family of mass timber products (Figure 1). These systems utilise both graded and ungraded timber in a variety of forms and section sizes and are normally formed in a factory using glue bonding, mechanical fixings or moisture movement to produce larger structural beam or slab components. The glued systems which primarily utilise ungraded timber are known generically as structural composite lumber (SCL), this family includes Laminate Veneer Lumber (LVL), Parallel Strand Lumber (PSL) and Laminated Strand Lumber (LSL) with their constitution reflecting their name. SCL products are generally produced to form beam type elements for heavy timber framing, truss members, as well as curved, tapered and arched structural shapes. The mass timber system that utilises dimensional graded timber in a similar such manner is Glue Laminated Timber (GLT) (Figure 2).

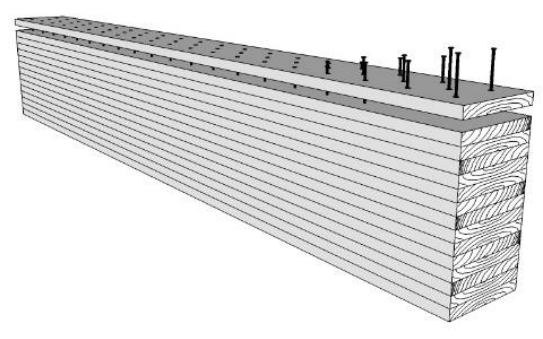

a) Nail Lam (NLT)

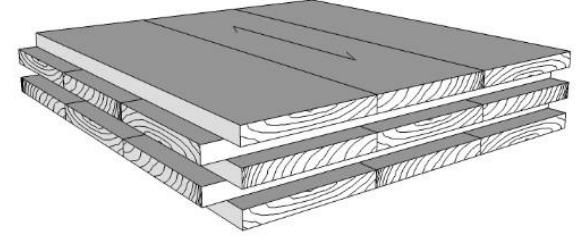

a) Cross Lam (CLT)

Figure 1 Examples of mass timber systems

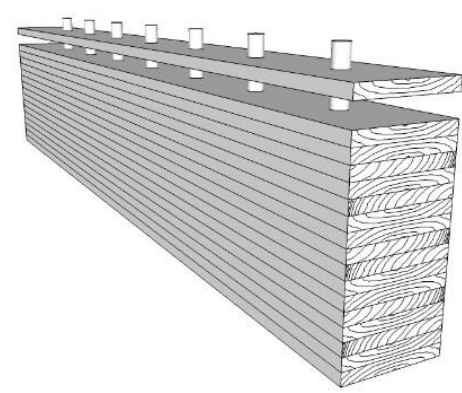

b) Dowel Lam (DLT)

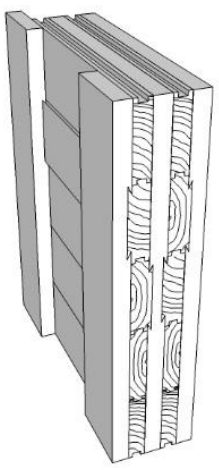

b) Interlocking CLT (iCLT) 


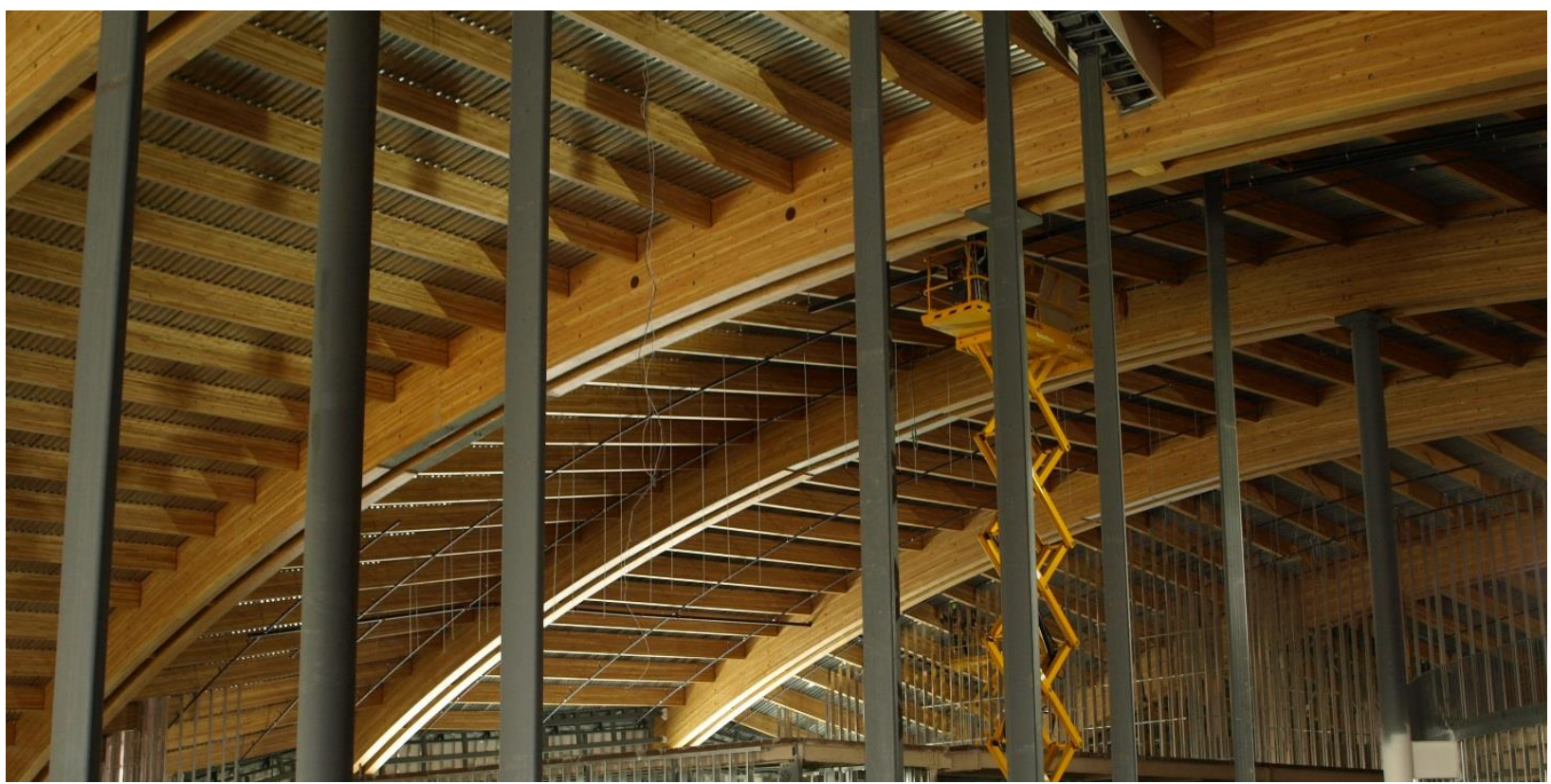

Figure 2 Curved glue laminated timber

It is however the panelised or slab forms of mass timber which have particularly moved the potential for use and application of timber in construction forward given their capability to form whole building envelopes often in combination with mass timber beam products and other construction materials in hybrid forms. Cross Laminated Timber (CLT), which can be formed from lower grade timber off-cuts that are reduced to strips or 'lamellae' and glued in perpendicular layers under high pressure by mechanical or vacuum compression, is the mass timber panel product which is most prominent in the market experiencing exponential international growth in application. This exponential growth is driven not only by the environment credentials of timber as a product but also by the structural attributes of the panels allowing timber to be used in building applications beyond normal limitations.

The first iterative steps to producing CLT were pioneered in the 1980's by Julius Natterer, a German engineer and professor for timber at the Ecole Poly-technique Fédérale de Lausanne, by forming one-way spanning panels from lamination of wood planks held together by nails, screws or dowels to form solid, one-way spanning panels now referred to as nail-lam (NLT), dowel-lam (DLT) or 'Brettstapel' (Wilson, 2016). DLT and NLT are therefore regarded as being mechanically laminated and in the case of DLT moisture movement is additionally used for connectivity. Softwood timber lamellae of approximately $15 \%( \pm 3 \%)$ moisture content are stacked in one plane and connected with hardwood timber dowels which are of a lower moisture content, normally $6 \%$. The dowels swell and the lamellas shrink locking the system together. Also utilising moisture control is interlocking CLT or iCLT whereby dovetailed notches are interfaced with a nested key to create multi-cross-laminated panels that range from 3-7 layers of three-inch stock softwood. The layers are cut with traditional Computer Numerical Controll (CNC) routers, assembled by hand and then pressed with a mobile hydraulic press. Given its structural credentials iCLT is only consider suitable for low to mid-rise construction but does offer a low cost way of utilising low quality, often diseased timber which would otherwise be wasted (Smith, 2011). 


\section{Application of Products}

The above described relatively simple methods of optimising and combining lower grade timber have enhanced the potential use and applications of wood in construction by simply improving the consistency of the product, its structural credentials and available section sizes particularly when considering CLT. All the mass timber products are normally fabricated offsite, mechanical lamination can take place in situ but undertaking production in a factory environment enhances productivity and provides higher levels of quality assurance. With respect to the glued systems factory conditions are necessary for relative humidity control given the dimensional constraints of the timber and adhesive curing requirements during the fabrication process. In addition to this, the mass timber products are required to conform to relevant standards for conformity within the given region for example 'EN 16351 Timber structures - Cross laminated timber - Requirements' (BSI, 2015) for CLT in Europe. In addition to this, within the factory environment, modern measurement devices are utilised to detect defects, thereby allowing them to be removed from the raw material and enabling longer more consistent lengths of lamella material to be formed through glued finger jointing. The lamellae are then planed for high levels of dimensional tolerance and the structural performance characteristic ascertained via in-line acoustic grading machines. The use of these modern measurement techniques facilitates an optimisation of the material during the cross lamination process whereby higher grade material can be utilised more effectively for structural performance and aesthetic appearance, with reduced levels of knots on the external facing surface when it is to be exposed for example.

Once fabricated the mass timber product is normally cut to the required shape and size for the end application via CNC (computer numeric control) saws which have the capability of cutting in almost any direction with the precision necessary to form openings, services voids or acoustic performance enhancing profiles. To streamline these processes the $\mathrm{CNC}$ operations will be linked to computer aided design (CAD) and computer aided manufacture (CAM) software. It is worth noting that this approach can also be utilised on Nail Laminated Timber (NLT) when aluminium nails are utilised for fabrication. These offsite manufactured mass timber products can then either be shipped direct to site or formed into offsite volumetric modules that can be taken to a high level of finish with windows doors, external cladding and internal linings and services included (Figure 3).

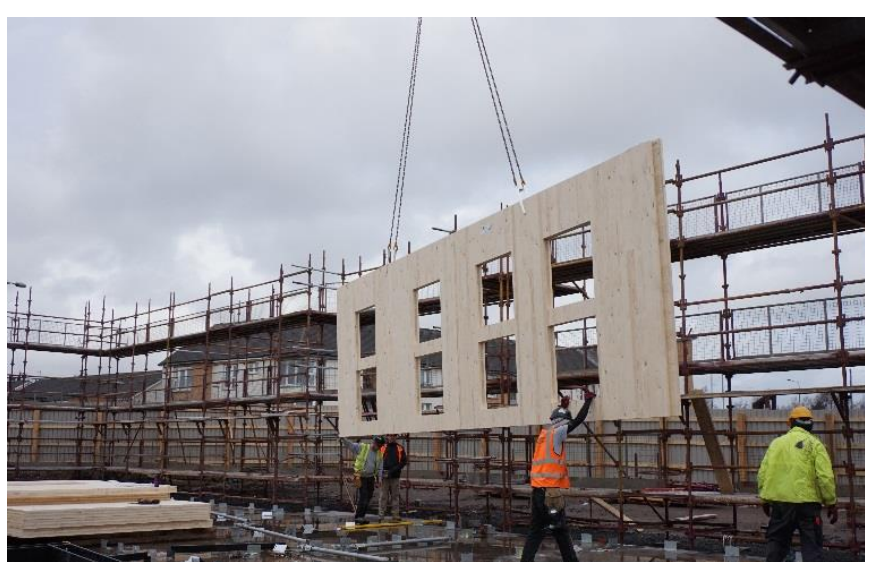

a) CLT with preformed openings being installed onsite

Figure 3 In-situ and enhanced volumetric systems

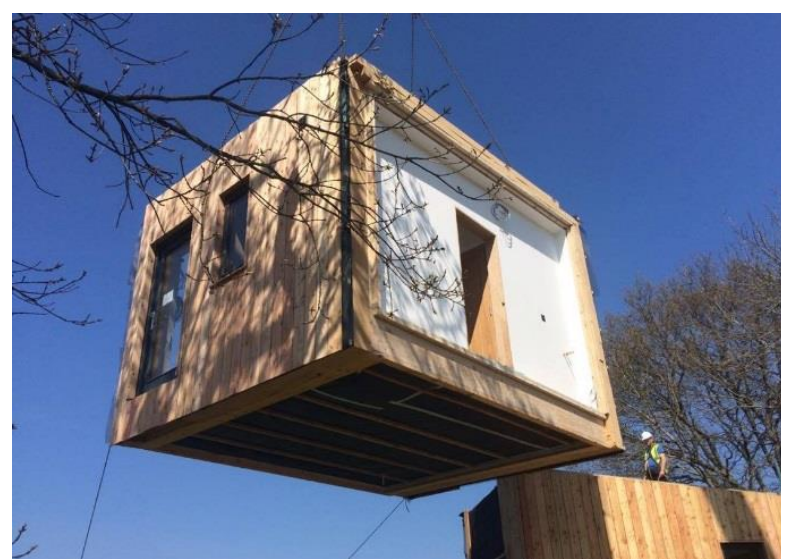

b) Enhanced volumetric CLT module (courtesy of Carbon Dynamic) 


\section{THE CASE FOR OFFSITE MASS TIMBER}

\section{Advantages and barriers}

Offsite massive timber systems can offer considerable advantages over more traditional forms of construction particularly when utilising local timber resource. Responsibly sourced timber has inherent environmental credentials given it sequestrates carbon, prolonging this sequestration in energy efficient buildings that conserve energy can help reduce the environment impact of construction. This is fundamentally important, given that buildings account for approximately half of all our extracted materials and energy consumption and about one third of our water consumption (European Commission, 2014). In addition to this, a localised supply chain can reduce transport emissions as well as provide jobs, stimulating wealth creation. Combining economic and environmental prosperity in this manner and ensuring the responsible management of resource during both the manufacture and useful life phases of a building means mass timber can work within the Circular Economy (CE) (Ellen MacArthur Foundation, 2016; Pomponi \& Moncaster 2017). The social, economic and environment value of utilising mass timber forms of construction therefore needs to be considered during the specification process. Specifying products for a project on material cost alone does not consider the wider benefits of mass timber and as a result other materials and systems can be wrongly viewed as being more competitive. For example, mass timber construction has been demonstrated to reduce construction time on projects by up to $20 \%$ when compared to more traditional methods, this can be of particular relevance when the time to building sign off impacts upon the return on investment (Smith, 2015).

There are, however, barriers to uptake, with a lack understanding of the benefits to such methods of construction combined with the sectors resistance to change often impinging upon progress. Manufacturing mass timber at scale and enhancing it further in an offsite environment does normally require high levels of capital investment which necessitates a pipeline of work to ensure a return. Given that this is the case collaborative partnerships between industry, government agency, trade organisation and academia are important when bringing mass timber products to market. These types of collaboration have the ability to stimulate the market by means of showcasing and disseminating information, ensuring systems compatibility within the regional regulatory context and importantly reducing the associated investment risk through the use of public funds to underpin the process.

\section{Design for Manufacture and Assembly + Disassembly (DfMA + D)}

The utilisation of mass timber products requires a change in design thinking particularly when the products are to be further formed to create full volumetric units with an enhanced level of finish. Designers need to take cognisance of the capabilities of the mass timber manufacturing process (Figure 4) (dimensional constraints, CNC cutting and routing capability etc) and follow on production activities (factory lifting capability, allowable space, available tools and equipment etc) to create the volumetric system. In addition the logistical arrangement both from a transport and site constraints perspective need to be taken in to account. Further, end of life or change of use should also be considered where possible such that the building components are demountable in the future for reconfiguration or alternative use. Facilitating this information and communication technology (ICT) system integration and ensuring an early design freeze are regarded as being of high importance. Digitisation and the emergence of integrated BIM 
platforms that facilitate the interoperability of softwares utilised during each stage of the mass timber production process can enhance volumetric unit creation, whilst improved on-site installation operations will further optimise overall performance. In addition to this, the use of virtual reality and augmented reality will facilitate knowledge exchange for upskilling as well as client and customer understanding. An integrated DfMA+D process combined with enhanced and early understanding across the project team will facilitate improved decision making allowing design freeze to take place and more added value in the factory.

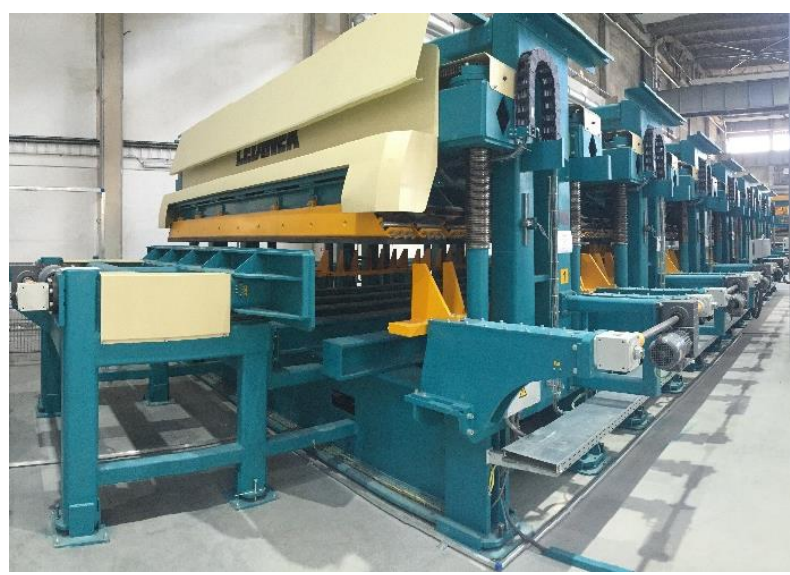

a) CLT mechanical press

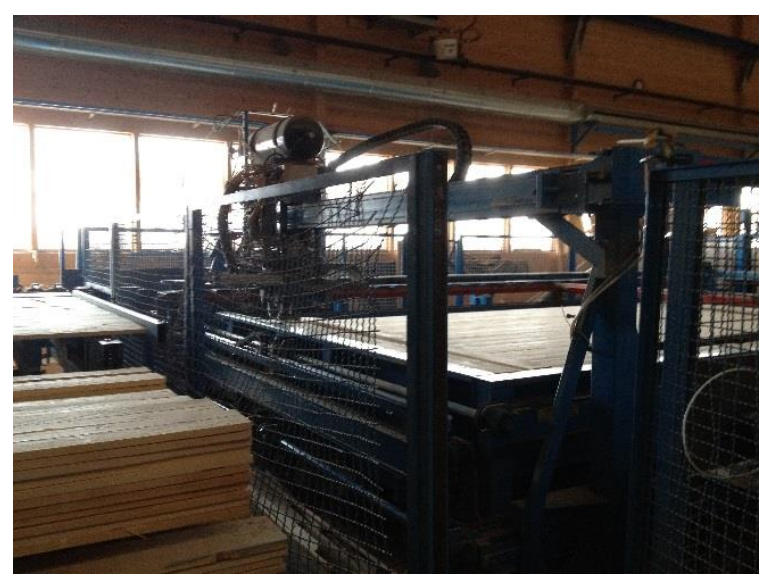

b) NLT nailing rig

Figure 4 Mass timber fabrication equipment

\section{UK MASS TIMBER EXPLORATION}

In the UK over half of the forest resource is grown in Scotland, where the most predominant species is Sitka Spruce and which accounts for approximately $50 \%$ of the UK softwood resource (FCS, 2011). Sitka is the therefore the main species utilised for commercial structural applications. There are other softwood species available with Scots pine (15\%), European, Hybrid and Japanese larches (8\%), Norway spruce (4\%) and Douglas fir (2\%) considered viable for structure. However, there is currently no mainstream mass timber production facility in the UK capable of supplying the volume market. Edinburgh Napier University has worked in collaboraiton with numerous industry partners in the Scottish context (CCG, MAKAR Construction, Carbon Dynamic, NorBuild et al) to investigate the potential for mass timber fabrication on commerical scale within Scotland with support from Scottish Enterprise, the Forestry Commision Scotland and the European Regional Development Fund. This exploration has included the assessment of the Scottish timber resource for the production of GluLam, Nail Lam, Dowel Lam (Figure 5) and Cross Lam with the predominant focus on Sitka spuce, but also considering other softwood species too. Larch in particular was considered given the potential onset of pyhytophthora ramorum disease and the corresponding need to find added value market opportunities. The technical reserach work undertaken primiarly focussed on the strucutral credentials of the products, comparing them relative to imported products, or European structural timber grades to establish viability as appropriate. In addition to this the products were also utilised within pilot projects in order to stimulate the supply chain, demonstrate technical compatibility, create infomation for specifiers whilst raising awareness. This case study content as well as full descriptions of the manufacture and applications of the various glued and nonglued systems including comparative data on their technical characteristics has been captured in 
"Mass Timber - an introduction to Solid Laminate Timber Systems" (Hairstans, 2018). The purpose of the publication is to benchmark the current international profile of mass timber systems whilst demonstrating the viable options that could be produced from the UK resource. It is envisaged that the dissemination of this work will be a milestone towards the production of mass timber products in the UK on a commercial scale.

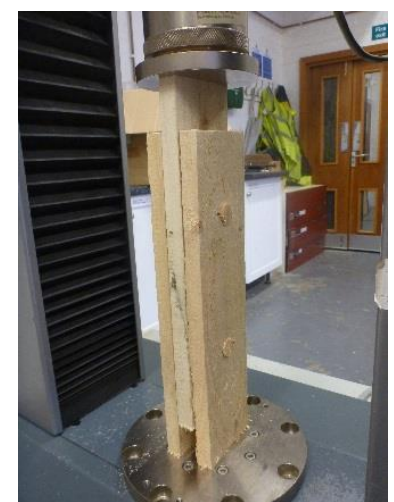

a) Structural testing of a Sitka spruce lamellae connection with birch dowels

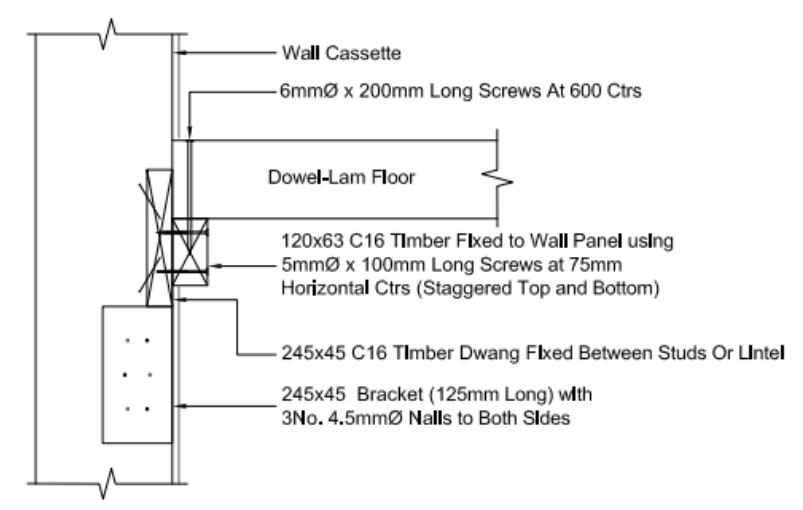

b) Structural detailing of DLT at floor to wall junction

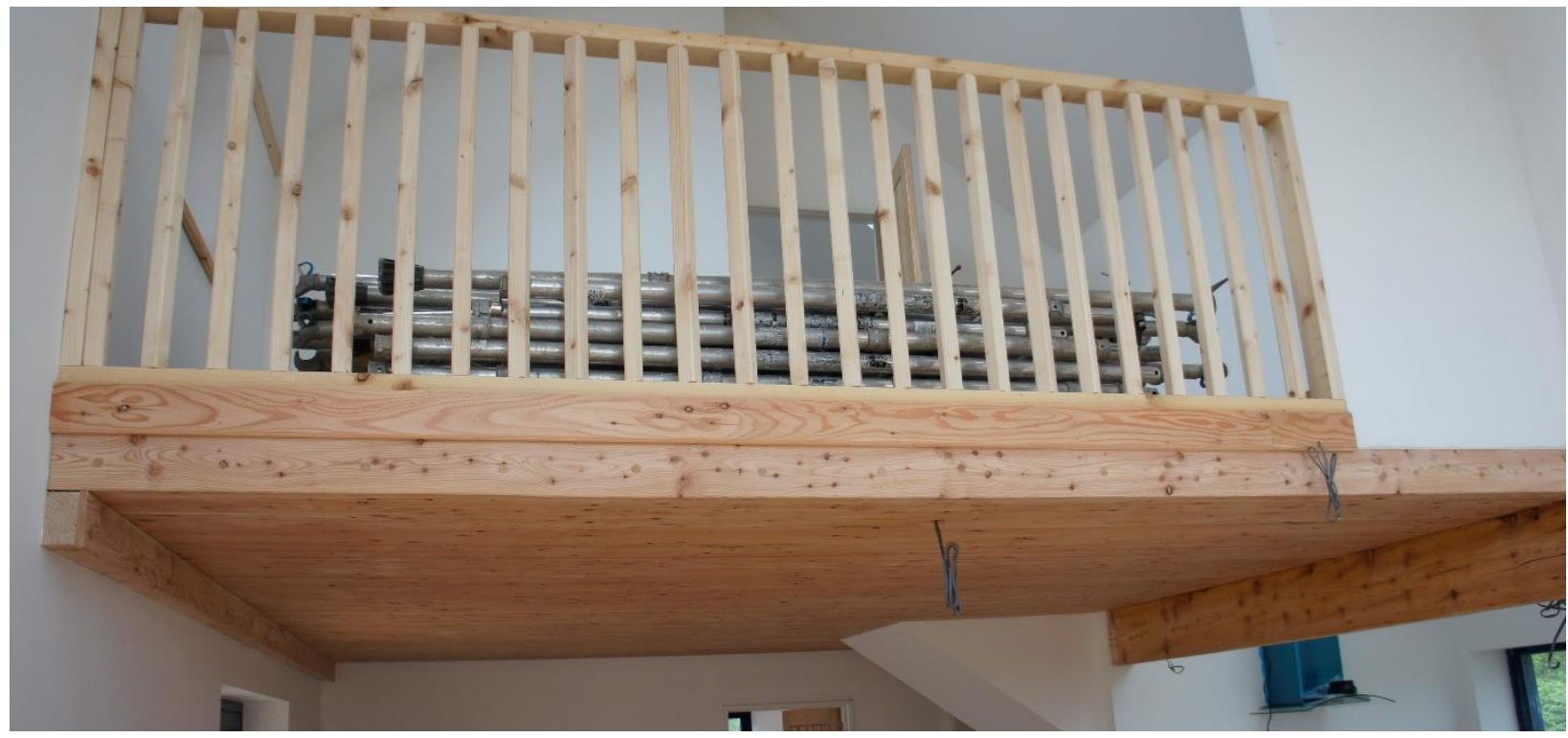

c) Pre-manufactured dowel lam floor from Larch

Figure 5 Dowel laminate timber

\section{CONCLUSION}

Mass timber encapsulates a wide range of solid laminate timber systems that can be formed from varying species and grades of timber. Inherently mass timber can offer a sustainable way of adding value to local timber resource and which can be further enhanced via follow on offsite prefabrication techniques. Mass timber comes in both beam and slab form, thereby lending itself to offsite, modular and volumetric forms of construction, essentially because it offers rigid units for transport and installation. These units, via a DfMA+D approach, can have openings preformed, internal and external finishes applied and services integrated, with due consideration 
taken to ensure longevity of use. The onset of digitisation and uptake of Building Information Modelling facilitates this approach. Additionally, enhanced product awareness via new digital technologies including augmented and virtually reality can assist with early design freeze such that more can be done in the factory. In order to move towards these more sophisticated and sustainable forms of construction the regional market needs to be stimulated in order to facilitate supply chain integration, improve knowledge and awareness and demonstrate technical compatibility and robustness. The work undertaken in the UK context has demonstrated such an approach and the benchmark outreach publication "Mass Timber - an introduction to Solid Laminate Timber Systems" (Hairstans, 2018) is considered to be a strategic milestone towards full commercial production of mass timber systems capable of being integrated with current offsite construction firms and future start-ups. However, future work is still required to fully demonstrate the economic case for mass timber in order to address client scepticism and there is also a need to create improved levels of guidance for DfMA $+\mathrm{D}$ approaches, and combinations of approaches, in order to ensure value return is maximised for the given circumstance. Continued evaluation and reporting of case studies utilising digital data acquisition techniques will help build this evidence base.

\section{ACKNOWLEDGEMENTS}

The authors would like to thank the numerous funders and industry partners involved with this research effort including, but not limited to, The European Regional Development Fund, Forestry Commission Scotland, Scottish Enterprise, MAKAR Construction, CCG(OSM), Carbon Dynamic and BSW Timber.

\section{REFERENCES}

BSI (2015) “Timber structures - Cross laminated timber - Requirements” British Standards Institution, ISBN 9780580766770

Forestry Commission. (2014, November 1). "Forestry Statistics 2014 - UK-Grown Timber." Retrieved from Forestry Commission: http://www.forestry.gov.uk/

Ellen Macarthur Foundation (2013) "Towards the circular economy - economic and business rationale for an accelerated transition" https://www.ellenmacarthurfoundation.org/

European Commission (2014) Communication from the commission to the European Parliament, the Council, the European Economic and Social Committee and the Committee of the Regions on resource efficiency opportunities in the building sector" Brussels, 1.7.2014, 445 final

Hairstans (2018) "Mass Timber - an introduction to Solid Laminate Timber Systems" Published by Arcamedia, ISBN 978-1-904320-11-1

Pomponi, F. \& Moncaster, A. (2017) "Circular economy for the built environment: A research framework", Journal of Cleaner Production 143, pp 710 - 718

Smith, R., Griffin, G. and Rice, T. (2015) "Solid Timber Construction: Process, Practice, Performance", USDA FPL and FPInnovations, www.rethinkwood.com/Solid Timber Construction Report

Smith, R.E. (2011). "Interlocking Cross-Laminated Timber: an alternative use of waste wood in design and construction. Convergence + Confluence”. Proceedings for the 2011

Conference of the Building Technology Educators' Society (BTES).

Wilson, P. (2017). "Cross Laminated Timber" in: (Jones D., Brischke C. Eds.) Performance of Bio-based Building Materials, Elsevier 